\title{
Algumas considerações sobre os homens no contexto da violência contra a mulher
}

\author{
Some considerations about men in the context of violence against women
}

Maria Lúcia Chaves Lima ${ }^{[a]}$, Ricardo Pimentel Méllo ${ }^{[b]}$

\footnotetext{
[a] Doutora em Psicologia Social pela Pontifícia Universidade Católica de São Paulo (PUC-SP), professora da Universidade Federal do Pará (UFPA), Belém, PA - Brasil, e-mail: marialuciacl@gmail.com

${ }^{[b]}$ Doutor em Psicologia Social pela Pontifícia Universidade Católica de São Paulo (PUC-SP), professor da Universidade Federal do Ceará (UFC), Fortaleza, CE - Brasil; e-mail: ricardo_pm@uol.com.br
}

Recebido: $12 / 01 / 2012$ Received: 01/12/2012

Aprovado: 04/04/2012 Approved: 04/04/2012

\begin{abstract}
Resumo
Este trabalho tem como objetivo problematizar os lugares geralmente destinados aos homens no contexto da violência contra a mulher. Como metodologia, fez-se uso de entrevistas com os profissionais que atuam na Delegacia da Mulher de Belém (PA), bem como observação atenta no cotidiano desse espaço. Como resultados da pesquisa, pode-se dizer que o ponto-chave da discussão foi uma nova naturalização: a "essência" violenta do homem abre espaço à socialização em uma cultura machista. Porém, mesmo considerando esses homens mais como "pais de família" do que "criminosos", a prisão ainda é o encaminhamento mais indicado. No máximo, adiciona-se ao encarceramento algum atendimento psicológico que funcionaria como uma forma de reeducação, um instrumento para adestrar e corrigir esses homens considerados "anormais". Conclui-se que, mais do que aprisionar os homens autores de violência ou oferecer um "tratamento psicológico" que sirva como mais uma tecnologia de controle, seria interessante proporcionar um espaço de escuta para homens e mulheres envolvidos em relacionamentos violentos; um espaço no qual seja possível instaurar a dúvida nos convictos padrões de gênero que produzem as situações de violência conjugal.
\end{abstract}

Palavras-chave: Homens. Violência contra a mulher. Terapêutica.

\begin{abstract}
The aim of this paper is discuss the places usually allocated to men in the context of violence against women. The methodology used was interviews with the professionals working in the Women's Police Station in Belém, Pará State, Brazil, as well as close observation of everyday life in space. As search results, we can say that the main point of this discussion revolves around a new naturalization: the "essence" of the violent man opens space for socialization in a sexist culture. But even considering these men more as "family men" than "criminals", the prison is still the most appropriate referral. At most, it is added to some psychological imprisonment would act as a form of rehabilitation, an instrument of training and correction for these men considered "abnormal". We conclude that, rather than imprison men perpetrators of violence or provide a "psychological treatment" to serve as an additional control technology, it would be interesting
\end{abstract}


to provide a space for listening to men and women involved in violent relationships; a space in which to establish doubt in the gender conviction that produce situations of domestic violence.

Keywords: Men. Violence against women. Therapeutics.

\section{Introduç̃̃o}

"Do rio que tudo arrasta, diz-se que é violento.
Mas ninguém chama violentas às margens que o
comprimem."
(Bertolt Brecht)

Este trabalho apresenta uma discussão a respeito dos lugares geralmente destinados aos homens no contexto da violência contra a mulher ${ }^{1}$, mais precisamente no cenário após a implantação da Lei n. 11.340, popularmente conhecida como Lei Maria da Penha. Trata-se do resultado de uma pesquisa realizada por meio de entrevistas com os/as profissionais que atuam na Delegacia da Mulher de Belém (PA), bem como observação atenta no cotidiano desse espaço.

Em relação ao conteúdo da Lei, o aspecto mais divulgado, de forma geral, é a punição mais severa infligida aos homens acusados de cometer violência contra a mulher. Porém, cabe destacar outro instrumento previsto na Lei Maria da Penha (Brasil, 2006): a possibilidade de o autor da violência frequentar "programas especiais para reeducação". 0 último item do Artigo 35 das disposições finais (Título VII) da Lei Maria da Penha diz que o Estado brasileiro poderá criar e promover, entre outras coisas, "centros de educação e de reabilitação para os agressores”. Há ainda a inclusão do parágrafo único ao Artigo 152 da Lei de Execução Penal, Lei n. 7210 de 1984 (Brasil, 1984), o qual diz que "o juiz poderá determinar o comparecimento obrigatório do agressor a programas de recuperação e reeducação".

Cabe ressaltar que, apesar de incluir medidas que visem a "reabilitação" dos autores de violência, a Lei não determina uma obrigatoriedade nem da criação, nem do comparecimento do homem ao que se chama de Centros de Reabilitação. Como foi destacado anteriormente, o verbo "poder" que aparece na Lei indica uma possibilidade e não uma prioridade. Além disso, não há nenhuma indicação ou explicação sobre esses "centros de reeducação". Inclusive, pode-se remeter essa "reeducação" ao estabelecimento prisional posto que, teoricamente, a cadeia teria como objetivo fazer com que o condenado restaurasse as normas sociais e fosse "reabilitado" ao convívio social extramuros.

Há, portanto, o reconhecimento na Lei Maria da Penha da necessidade de ações que envolvam homens imersos no contexto de violência doméstica e familiar, mas é instigante notar que esse personagem continua sendo tratado somente como "agressor", perpetuando uma cisão maniqueísta dessa situação. A referida lei não apresenta em nenhum momento a palavra "homem", referindo-se a este apenas como "agressor" (Dantas \& Méllo, 2008).

Tal reconhecimento da importância do envolvimento de homens nas ações destinadas à violência contra a mulher é um efeito da compreensão de que, para se atuar efetivamente neste campo, é fundamental discutir as relações de gênero produzidas socialmente, as formas de ser homem e de ser mulher que alimentam as bases simbólicas desse tipo de violência.

A pesquisa de Maria Filomena Gregori (1993), por exemplo, apoia-se no argumento de que as mulheres não são simplesmente "dominadas" pelos homens ou são meras "vítimas" da violência conjugal. Criticam-se, portanto, as abordagens nas quais os homens são sempre preconcebidos como algozes e as mulheres como vítimas, intensificando certa concepção essencialista de gênero (que tanto criticamos!) que direciona o homem à violência e a mulher, ao conformismo, dependência e vitimização, como se esta fosse incapaz de gerir a sua vida.

Indo de encontro aos essencialismos de gênero, uma corrente do movimento feminista passou a incluir os homens nas discussões sobre violência doméstica, problematizando assim as relações de gênero. Essa mudança de foco, antes exclusivo à

\footnotetext{
1 Adotamos a expressão "violência contra a mulher", no lugar de "violência de gênero", uma vez que este último termo não se refere unicamente às mulheres, podendo açambarcar situações de violência de homens entre si, assim como mulheres, adultos, crianças etc.
} 
defesa de direitos femininos, foi extremamente importante no sentido de não centrar apenas nos homens a responsabilidade pelos conflitos conjugais. Se realmente se deseja combater os crimes que atingem as mulheres, é fundamental incluir os homens, desenvolvendo políticas e uma franca discussão das relações de gênero instituídas socialmente. "Ao invés de procurar os culpados, é necessário identificar como se dá a relação, gerando menos sofrimento individual e possibilitando efetivamente transformações no âmbito das relações sociais 'generificadas', ou seja, orientadas pelas desigualdades de gênero" (Arilha, Unbehaum \& Medrado, 2001, p. 24).

Cremos que hoje em dia já exista um consenso em torno dessa posição. Entretanto, as ações efetivamente providenciadas parecem se restringir aos grupos de discussão que são formados em Juizados especializados em violência doméstica, pós-agressão, que inclusive acabam remetendo a discussão para o campo da doença, atribuindo ao uso das bebidas alcoólicas a "causa" das agressões que homens cometem contra as mulheres, forçando esses homens a frequentarem o grupo de Alcoólicos Anônimos.

Isso nos indica que os profissionais que atuam nesses casos trabalhando em serviços que buscam dar atenção aos homens, precisam incluí-los não somente como agressores, mas também como afetados pelas práticas caracterizadas como "machistas" que geram graves consequências para suas vidas. Assim, propomos pesquisar esses profissionais, no espaço considerado a porta de entrada para a visibilidade da violência que homens cometem contra mulheres: a Delegacia da Mulher. Que concepções têm das situações de violência com que se defrontam a cada dia de trabalho? Como compreendem a figura do homem nesse contexto de implantação da Lei Maria da Penha? Perpetuam ou deslocam a prática de essencializar homens como agressores? Quais os encaminhamentos indicados como formas de atenção a esses homens? Há proposição de medidas que vão além do encarceramento? Tais medidas também são adotadas como punição? Essas e outras questões-problemas nos impulsionaram nesta pesquisa.

\section{Método}

A pesquisa foi desenvolvida inicialmente por meio de observações no cotidiano da Delegacia da Mulher de Belém (PA). Essa etapa propiciou envolvimento e interação no espaço em questão, possibilitando mapear não só sua estrutura física, mas também como é ocupado, como funciona, quem desenvolve o que e onde. Entendemos a Delegacia como uma rede de elementos que se constitui como campo de pesquisa nos inúmeros cruzamentos de atores humanos e não humanos (Latour, 2001). Com isso queremos dizer que profissionais e usuários, assim como os espaços e objetos (não humanos) se inter-relacionam constituindo a Delegacia como tal. E a observação no cotidiano desse espaço é fundamental para a cartografia ${ }^{2}$ de sua dinâmica. Muitas vezes tal observação é nominada como "observação participante" ${ }^{3}$, não sendo neutra e exigindo do "observador" convivência com o que está ocorrendo (não apenas fazendo registros de suas observações, mas também, estabelecendo interlocução) ${ }^{4}$.

A permissão para a realização da pesquisa na Delegacia da Mulher foi concedida por meio de um procedimento simples. Apresentamos o projeto de pesquisa à coordenadora do setor social da Delegacia, indicada pela policial que nos recebeu como o setor responsável por autorizar a realização de investigações naquele espaço. Em uma reunião, informamos se tratar de uma pesquisa vinculada ao Programa de Pós-Graduação em Psicologia da Universidade Federal do Pará, assim como os seus objetivos e a metodologia que almejávamos utilizar. Aprovada a proposta, começamos a participar do cotidiano das práticas da Delegacia. E a primeira ação foi muito simples: sentamos no salão principal da Delegacia e ficamos atentos às pessoas, público e profissionais, às práticas, movimentos, encaminhamentos etc.

As observações na Delegacia tinham duração média de duas horas, mas algumas perduraram por até cinco horas; isso dependia dos acontecimentos estabelecidos, da espera por algum funcionário a ser entrevistado etc. As idas à Delegacia eram organizadas de modo a contemplar todos os dias da semana e

2 Utilizamos a noção de cartografia criada por Foucault que se disse um cartógrafo (Cf. Deleuze, 1991, p. 53) que remete a busca das condições de emergência de saberes, de práticas de uma dada época.

3 Importante sinalizar que consideramos que não há observação sem que haja a participação do "observador".

4 Sem dúvida a Antropologia, com os trabalhos de Malinowski, como o clássico Os Argonautas no Pacífico Ocidental, inaugurou esse tipo procedimento que em meados do século XX teve grande impulso em nosso país com a publicação de obras importantes como: Barbier (1985); Brandão (1984); Ezpeleta e Rockwell (1986).

Psicol. Argum. 2013 jul./set., 31 (74), 425-435 
todos os turnos e horários possíveis. A única exceção foi a madrugada. Seguindo a orientação de um policial, não ficávamos depois das 22 horas na Delegacia, pois, segundo ele, era perigoso. A própria equipe policial não ficava no salão principal da Delegacia, que permanecia aberto durante a madrugada.

Após pouco mais de um mês de observação, já familiarizados com a dinâmica da Delegacia, iniciamos as entrevistas com os profissionais que ali atuam. A entrevista foi escolhida como metodologia, pois propicia uma interação face a face constantemente negociada, permitindo construir versões práticas sobre os temas colocados em pauta. A associação entre entrevista e observação se mostrou complementar, tal como indica Mendes (2004, p. 9): "A entrevista tem vantagens e permite apreender aspectos que a observação participante não permite. A observação participante prolongada dá, por outro lado, uma densidade analítica impossível de conseguir com um contacto restrito de umas horas com os entrevistados".

A entrevista também é uma maneira de pesquisar como as pessoas mantêm, transformam e desafiam certos posicionamentos estabelecidos (Pinheiro, 2000). As entrevistas foram desenvolvidas de forma a favorecer momentos de partilha, construção e transformação de posicionamentos, e, precisamente por esse motivo, foram feitas de forma semiestruturadas, ou seja, a partir de um roteiro preestabelecido, mas receptível a interrogações que foram surgindo no seu desenrolar. As perguntas iniciais buscaram estabelecer certa condição de confiabilidade. Por isso, a entrevista iniciava com questões referentes à atuação profissional dos entrevistados para posteriormente se desdobrar em indagações mais específicas referentes à Lei Maria da Penha, às impressões que eles tinham sobre os homens denunciados por violência contra a mulher e sobre os encaminhamentos que eles/elas acreditavam ser indicados a tais homens.

Não houve o estabelecimento prévio do número de entrevistas a serem realizadas. Contudo, durante o desenvolvimento da pesquisa, estabelecemos um único critério: o de entrevistar pelo menos um/uma profissional de cada cargo exercido na Delegacia. Ressalte-se que, quando o cargo era ocupado por pessoas de ambos os "sexos", faríamos no mínimo duas entrevistas, uma com o homem e outra com a mulher com o intuito de avaliar se havia diferenças entre os discursos articulados por eles ${ }^{5}$.

Efetuaram-se, então, 12 entrevistas distribuídas entre os dois setores de atuação na Delegacia da Mulher identificados durante o período de observação: o setor social e o setor policial. No setor social entrevistamos duas psicólogas e duas assistentes sociais. Do setor policial, participaram duas delegadas, um escrivão e uma escrivã, um investigador e uma investigadora, um auxiliar técnico e um motorista.

\section{Resultados e discussão}

A partir dessa inserção no cotidiano da Delegacia da Mulher, com as observações e entrevistas realizadas, apresentamos três aspectos que se mostraram relevantes durante o processo. São eles: a) o caráter punitivo da Lei Maria da Penha; b) as concepções sobre os homens autores de violência; c) os encaminhamentos que os/as profissionais indicam para tais homens. Tais aspectos serão acompanhados de indagações, críticas, incitações, confusões, dúvidas e versões.

\section{Sobre o caráter punitivo da Lei Maria da Penha}

Em todas as entrevistas realizadas com profissionais na Delegacia da Mulher, a Lei Maria da Penha foi considerada um grande avanço tanto para as mulheres, que antes não eram dignamente amparadas quando em situação de violência, quanto para o setor policial dedicado à violência doméstica, pois este passou a ser mais respeitado pela sociedade e pelos demais setores da polícia.

Em face da pergunta sobre qual seria a maior novidade da Lei, duas profissionais indicaram as medidas protetivas asseguradas; os/as demais elegeram a punição mais severa ao considerado "agressor", como se observa nos trechos a seguir:

Pesquisadora: E qual é a maior novidade que a lei trouxe? Investigadora: É a prisão para o agressor. Ela possibilita que o agressor seja preso em flagrante ou tenha a sua prisão preventiva decretada. Porque antes era a 9.099 e eram aplicadas as penas pecuniárias: cesta bá-

\footnotetext{
5 Algo, porém, que não fora observado no decorrer das análises.
} 
sica, trabalho voluntário. E a violência doméstica hoje é aplicada na 11.340, onde prevê a prisão.

Pesquisadora: Mas, para você, qual é a maior vantagem que a lei trouxe?

Psicóloga 2: Bem, a maior novidade é realmente hoje o homem passar a ter antecedentes criminais a partir do momento em que a mulher faz a queixa na polícia. A maior novidade mesmo é que hoje ele pode ser preso. E também teve a questão das próprias prisões em flagrante.

0 mesmo aspecto que veio dar mais respeito ao serviço oferecido na Delegacia da Mulher - a punição rigorosa - produziu, segundo os dados da própria Delegacia, uma redução no número das denúncias realizadas. Alguns profissionais entrevistados acreditam que a lei veio muito severa e isso produz o efeito oposto do que ela se propôs, pois, segundo eles, muitas mulheres, receosas com a possibilidade de cárcere do companheiro, optam pela convocação social. Tal intervenção, feita pelo setor social, consiste em uma conversa com o casal sem caráter punitivo e sem o registro de antecedentes criminais.

Essas considerações incitam a crítica de que a Lei Maria da Penha se limita em combater a violência contra a mulher por meio de medidas punitivas. Esse tipo de violência, ocorrida entre pares em relações afetivas e conjugais, apresenta matizes muito específicas. A procura pelos serviços da Delegacia da Mulher pode ser a busca de uma alternativa para a solução de seus conflitos conjugais. Mas será que a mulher quer o fim da união, decorrente da prisão do companheiro, ou uma vida sem violência com ele?

São questões que circulam em nossa sociedade, inclusive em músicas como "Molambo", gravada primeiramente por Elizeth Cardoso, em 1953, e depois, na década de 1970, pela cantora Maysa. O cantor Cauby Peixoto também gravou essa música, mudando o pronome de "ele" para "ela" (refere-se ao sofrimento de um homem), nos fazendo crer que esse sentimento ambíguo não tem exclusividade em termos de gênero. Aliás, a música foi composta por dois homens (Jaime Florence e Augusto Mesquita). Também o fato de uma cantora de família rica e tradicional como Maysa gravar a canção nos indica que a situação evocada pelo amor român- tico captura também sem discriminar classe social (os autores eram de Vila Isabel, bairro boêmio do Rio de Janeiro). Segundo o Dicionário Houaiss (2001), "molambo" significa: roto, sujo, em mau estado; indivíduo sem determinação e firmeza. Assim, a letra, em sua primeira gravação, apresenta o sentimento de uma mulher que vive a ambiguidade de amar um homem que a abandonou, ainda que tenha consciência da situação e, inclusive, de que será "malfalada" pela sociedade:

Eu sei que vocês vão dizer

Que era tudo mentira, que não pode ser

Que depois de tudo o que ele me fez

Eu jamais deveria aceitá-la outra vez

Pensei que assim procedendo

Me exponho ao desprezo de todos vocês

Lamento, mas fiquem sabendo

Que ele voltou e comigo ficou

Ficou pra matar a saudade

A tremenda saudade que não me deixou

Que não me deu sossego um momento sequer

Desde o dia em que ele me abandonou

Ficou pra impedir que a loucura

Fizesse de mim um molambo qualquer

Ficou desta vez para sempre

Se Deus quiser... ${ }^{6}$

Assim, acreditamos que a punição não leva em consideração a delicada relação existente na parceria conjugal. Os homens, para algumas das mulheres, não são só agressores, mas são companheiros, amantes, pais dos filhos, provedores. Diante da complexidade de experiências existentes nessa relação, cabe entender quem são esses homens para aqueles profissionais que têm como função ouvi-los, autuá-los, condená-los.

\section{Sobre os homens autores de violência contra a mulher}

Um aspecto interessante que emergiu das entrevistas foi a distinção entre "agressores" e "criminosos". Os homens denunciados na Delegacia da Mulher não são criminosos, apesar de terem cometido um crime.

\footnotetext{
${ }^{6}$ Florence, J., \& Mesquita, A. (1953). Molambo [Gravado por Elizeth Cardoso]. Em Enluarada [CD]. Rio de Janeiro: Copacabana.
} (1998).

Psicol. Argum. 2013 jul./set., 31 (74), 425-435 
Pesquisadora: Você acha importante, então, conversar com os presos?

Investigador: $E$ porque a gente não lida com bandido, marginal ... Assim, bandido, né? A gente lida mais com pai de família. Porque o agressor, a maioria deles são pais de família. Nenhum pai de família escapa dessa situação.

Percebe-se aí uma diferença entre os "bandidos", aqueles que roubam, matam etc., e os "agressores", vistos como "pais de família". Ser denunciado por praticar um ato de violência contra a mulher não significa ser um criminoso, apesar de esse ato ser considerado um crime. Na fala do investigador entrevistado, percebe-se um viés de fatalidade quando diz que "nenhum pai de família escapa dessa situação". Nesse momento, ele naturaliza a violência contra a mulher, como se fosse algo inevitável e inerente à posição de "pai de família", ou, em última análise, à própria posição de homem.

A concepção do que é ser homem, mais especificamente "homem-agressor", para os profissionais entrevistados, transita entre dois eixos "explicativos": (1) a socialização, a qual envolve a educação em uma cultura machista e a vivência da infância de forma violenta, e (2) o uso de bebidas alcoólicas.

De maneira geral, não há nas entrevistas a afirmação de que o homem é naturalmente mais violento do que a mulher. 0 investigador e o escrivão se referem à violência como "inerente ao ser humano" (e não apenas ao homem), todos os entrevistados remetem os casos de violência contra a mulher ao processo de socialização a que grande parte dos homens compartilha. Ou seja, o lugar antes ocupado pela natureza violenta foi substituído pela educação diferenciada entre homens e mulheres, uma vez que, segundo os relatos, em uma sociedade machista, os homens são ensinados a serem agressivos e ativos e as mulheres, dóceis e passivas.

Pesquisadora: $O$ que a senhora acha desses homens que cometem violência contra a mulher?

Assistente social 1: ... Quase sempre eles se remetem à infância, da forma com que eles foram tratados. Eles não têm consciência que isso é um aspecto do machismo. Não. Eles cresceram ouvindo que o homem manda mais que a mulher, que se ele tem poder econômico (a maioria das mulheres que a gente atende não tem uma renda), ele pode mandar, pode obrigar; que se ele é casado com ela, todas às vezes que ele tiver com apetite sexual, ela tem que satisfazer....
Pesquisadora: Mas o que explicaria essa violência? Delegada 1: Acho que é todo um processo que a gente mesmo enquanto mulher repassa para os nossos filhos. A menina é educada pra brincar de boneca e o menino pra jogar bola. A menina é criada pra ser obediente e o menino não pode chorar.

Observa-se uma nova naturalização da violência contra a mulher, agora via socialização e não mais devido a um instinto violento que os homens supostamente possuem. Essa proposta diz, então, que os homens são violentos porque foram educados a agir dessa forma. Em outras palavras, da mesma maneira que a tese da violência inata, tal consideração de que a violência é fruto de socialização continua a naturalizar a violência, sem questioná-la. Podemos perceber que as explicações advêm de matrizes diferentes, mas as consequências parecem ser as mesmas no sentido de não propor mudanças efetivas. Cai-se no discurso da culpabilização e vitimização: a culpa é da natureza humana ou da cultura e todos são vítimas. Adiante poderemos ver com mais detalhes essas posições.

Seguindo a linha de raciocínio que chamaremos de "socializatória", que credita à cultura a culpa pela existência de "homens violentos", a infância infeliz também emerge como explicação para a agressão à mulher. Com efeito, os profissionais relatam que muitos dos homens denunciados viveram em um ambiente em que era comum e constante a violência contra a mulher e que agora eles simplesmente reproduzem esse "padrão social" oriundo da infância. Viver em um "lar violento" é uma derivação da hipótese socializatória e serve como justificativa para explicar a situação de violência conjugal. Portanto, essa perspectiva, quase fatalista, não deixa brechas para que essas pessoas criem outras formas de viver e conviver, circunscrevendo-as em um círculo irrevogável. Isso não significa negar a possibilidade de que pessoas (homens e mulheres) que vivenciaram situações de violência possam agir de forma também violenta; o problema é atribuir uma relação de causalidade entre esses acontecimentos. Não dá espaço para a criação de novas formas de ser.

Além disso, a hipótese socializatória localiza o problema da violência e, mais ainda, das relações de gênero vividas na atualidade, unicamente na esfera familiar - por se considerar que esta seja a principal instituição socializadora, seguindo teorias clássicas que circulam no meio científico, como as de Berger e Luckmann (1973) —, deslocando-a 
do contexto social mais amplo. Corre-se o risco de cristalizar a violência como expressão oriunda exclusivamente do ambiente familiar, esquecendo-se de que a violência que emerge no espaço doméstico envolve questões políticas mais amplas, como as construções binárias e heterocentradas de gênero legitimadas socialmente.

Como vimos de forma breve, a hipótese socializatória reafirma que os homens são "vítimas da sociedade", como se eles não tivessem a possibilidade de resistir ao modelo hegemônico de masculinidade.

Pesquisadora: E o que a senhora acha desses homens? Delegada 1: Que eles também são vítimas de um processo, do machismo que na nossa sociedade é histórico ... O homem bate porque é homem e a mulher apanha porque é mulher ... Então essa violência é reproduzida diariamente e o homem acaba reproduzindo e vai passando de geração em geração.

Não devemos concluir apressadamente que a hipótese socializatória propõe uma inversão da posição de vítima ocupada pelas mulheres para os homens. Todavia, argumentamos que permanecer nessa discussão sobre "quem é vítima do quê", além de ser um debate estéril, perpetua uma visão maniqueísta, como se realmente tivesse a vítima de um lado e o culpado de outro ${ }^{7}$. 0 importante é mudar o foco de análise e, com isso, essas visões binárias simplistas. Para tanto, cremos que a noção de poder desenvolvida por Michel Foucault (2003) pode se constituir em uma importante ferramenta de análise. 0 autor abandona a ideia de um modelo centralizador do poder, como se houvesse um ponto do qual ele seja emanado (os homens, ou o Estado, ou a família). Como compreensão da dinâmica das relações de poder, deve-se ter como modelo de análise uma rede que permeia todo o corpo social, articulando e integrando os diferentes focos de poder (homens, mulheres, gênero, família, leis, tradições, Estado, delegacias etc.) que se apoiam uns nos outros. Portanto, é necessário avançarmos para além da atribuição de quem é vítima e quem é culpado.

0 segundo eixo recorrido pelos entrevistados para explicar a violência contra a mulher é o uso de bebidas alcoólicas. Se o homem é ensinado, e muitas vezes incentivado a ser agressivo, o álcool é considerado um elemento potencializador dessa agressividade.

Pesquisadora: E qual a principal queixa das mulheres atendidas aqui?

Escrivã: Que o marido bebe muito. A bebida é 99\% dos casos. A meu ver, né? A bebida causa todos os males dessa vida, não só os casos de violência doméstica, mas a violência toda que impera aí. Todo esse desajuste familiar gerado por isso: álcool, droga, né? Claro, se a gente for puxar é uma coisa tão infinita, mas o principal é a bebida. A maioria, no final de semana, bebe, vai pra farra, aí vêm todos esses problemas quando chega em casa: a mulher não pode nem olhar pra ele que ele já vai querer partir pra violência.

Há uma associação entre a ação violenta e ingestão de bebidas alcoólicas, como se esse hábito fosse determinante para a ocorrência da agressão conjugal. O uso dessa substância aparece como sendo a culpada pela ação violenta e, assim, exime de certa forma a responsabilidade do autor da violência. Identifica-se o inimigo (a bebida) e a vítima de seu ataque (o homem). De acordo com essa concepção, um homem pode até não ser agressivo, porém, após a ingestão de bebidas alcoólicas, ele se transforma e "não se responsabiliza pelos seus atos", como dito popularmente. 0 mal está na bebida! ${ }^{8}$. A culpabilização das drogas as torna actantes ${ }^{9}$ importantíssimos que, se não excluem, minoram diversas outras situações que, aliadas, poderiam desencadear situações de violência: experiência de impotência e desamparo (Costa, 1984), estímulo à competição, narcisismo, pobreza, desemprego e crescimento da população, impunidade de criminosos endinheirados etc.

\footnotetext{
7 Neste caso aparece a figura do bode expiatório a que se refere René Girard (1990) em seu trabalho sobre a violência e sua relação com o sagrado.

8 A pesquisa realizada por Ricardo Pimentel Méllo e Luísa Furtado (2010) aborda especificamente este aspecto da relação entre o uso do álcool como responsável pela violência contra a mulher.

9 Como a palavra "ator" se limita a humanos, empresta-se da semiótica o termo "actantes" para incluir os não humanos na definição. Dessa forma, um actante pode ser definido como qualquer pessoa, instituição ou coisa que tenha agência, que produza efeito no mundo (Latour, 2001).
}

Psicol. Argum. 2013 jul./set., 31 (74), 425-435 
Tal como Gregori (1993), não objetivamos negar a possibilidade que o álcool e outras drogas têm de inibir algumas censuras e desencadear atos violentos, mas entendemos que "eles não têm o poder de determinar categoricamente e genericamente a incidência de violência" (Gregori, 1993, p. 143). Além disso, explicar a violência contra a mulher a partir dessa perspectiva é desconsiderar razões mais intrínsecas do problema: as relações de gênero tradicionais que ainda persistem na atualidade. Eleger um "outro" como o culpado pela violência é uma atitude simplista e pouco útil na busca de alternativas para a questão. Como afirma Furtado (2010, pp. 29-30):

há necessidade de se problematizar as relações entre a ingestão de bebida alcoólica e a violência conjugal a fim de que essa não se torne uma relação causal e simplista que perde de vista a produção das masculinidades e das feminilidades, ... tendo sempre em vista que as discussões sobre violência e bebida alcoólica são importantes, mas elas não podem dispensar ponderações sobre modos de vida, sobre amizade, sobre os modos como nos relacionamos e nos constituímos.

Além do mais, a responsabilidade da agressão deslocada para a bebida alcoólica põe em foco outra questão: os chamados "agressores" precisam de atendimento psicossocial porque são viciados. Em outros termos, o problema não está na agressividade, nas relações de gênero que permeiam os relacionamentos conjugais, mas no uso de bebidas alcoólicas, tanto que o encaminhamento dado a esses homens é direcioná-los ao grupo Alcoólicos Anônimos, como se, de forma genérica, ao tratar o problema do alcoolismo fosse solucionado o da violência.

O que se percebe, então, é a produção de um tipo de "agressor": aquele que presenciou o pai bater na mãe, que bebe, é pobre e não tem condições de manter a família. Entretanto, pode-se afirmar que nem todo homem que se afina a esse "tipo" agride sua companheira. 0 que há de errado, então, com os "agressores"? Esse discurso abre precedente para a submissão desse homem a uma série de tecnologias para tentar modificar o que está "errado".
0 "agressor" - pois o homem já está capturado nessa identidade - é (ou deveria ser) submetido tanto a uma tecnologia penal, a prisão, quanto a uma tecnologia terapêutica capaz de regenerá-lo (Foucault, 2000).

\section{Sobre os encaminhamentos aos homens}

Como já mencionado, a maior novidade da Lei Maria da Penha elegida pelos profissionais foi a punição mais rigorosa ao chamado "agressor"10. Isso indica que consideram adequada a prisão a quem comete violência contra a mulher.

Pesquisadora: A senhora acha que em alguns casos a prisão é vital?

Delegada 2: Com toda certeza. Acho que tem que ter a punição realmente. Junto com a punição aquele trabalho que, a gente sabe que não existe, que é o trabalho junto a esse agressor.

Mesmo que a maioria dos funcionários entrevistados considere a prisão como a grande conquista trazida pela Lei Maria da Penha, eles reconhecem que a cadeia por si só não é capaz de provocar uma transformação no "prisioneiro". De acordo com Foucault (2003), a prisão desde seu início (século XIX) foi criada com o intuito de ser uma "empresa de modificação de indivíduos", porém o seu fracasso foi imediato e registrado quase que ao mesmo tempo em que o seu projeto era desenvolvido. Ou seja, não é de hoje que se sabe que a prisão não provoca mudanças positivas na conduta das pessoas; ao contrário, desde o século XIX, a prisão fora denunciada como fábrica de criminosos, que inclusive pode transformar o infrator ocasional em delinquente (Foucault, 2003).

Como a maioria dos entrevistados tem clareza de que encarcerar o "agressor" não resulta em melhor conduta futura, eles sinalizam a importância de algum tipo de atendimento "psicológico" aos homens acusados de violência contra a mulher. 0 auxiliar técnico, por exemplo, questiona a eficácia da prisão como um instrumento adequado para prevenir os casos de violência doméstica:

\footnotetext{
${ }^{10}$ A exceção foi uma assistente social, com trajetória e militância no movimento feminista, que elege como a maior conquista da Lei Maria da Penha as medidas protetivas à mulher, tais como: o afastamento do lar do homem autor da violência, suspensão do porte de armas, proibição de contato físico com a mulher "ofendida", fixando-se um limite mínimo de distância entre eles etc.
}

Psicol. Argum. 2013 jul./set., 31 (74), 425-435 
Pesquisadora: O senhor acha que a prisão é uma punição eficaz?

Auxiliar técnico: Não, não acho. Eu não acho que seja tão eficaz. Veja bem uma coisa: se fosse tão eficaz, o cara seria preso só uma vez. E isso eu não digo só em relação à violência doméstica, digo em termos de violência em geral. o cara seria preso e depois parou. Então, eu não acho que seja por aí. Eu acho que deveria ser feito também um trabalho, não só com a mulher como vítima, mas com os homens agressores, porque eles são doentes, eles têm problemas, eles têm algum distúrbio. Então, eles também teriam que ser trabalhados, tá entendendo? Não sei se até dentro da cela ou se eles fossem chamados pra uma psicoterapia fora da cela pra fazer um trabalho com esse pessoal aqui dentro, pra que eles não ficassem no ócio aí. A gente sabe que a mente vazia é oficina do diabo.

Na fala do auxiliar técnico, percebe-se a crítica à prisão pela reincidência: se prender fosse a melhor alternativa, o homem não voltaria a cometer atos de violência contra a mulher e ser denunciado novamente. A partir do reconhecido fracasso da prisão, ele sugere um atendimento psicológico ao "condenado". Mesmo questionando a eficácia da prisão, o profissional sustenta que o atendimento psicológico ao homem seja feito "dentro ou fora da cela", ou seja, esse homem a ser "tratado" está preso. Isso indica que a prisão continua sendo a forma básica de punir e o tratamento psicológico é uma medida acessória. A prisão é essencial, é o justo; o tratamento é um aspecto coadjuvante, ainda que muito importante para esses casos.

Assim como o auxiliar técnico, a grande maioria dos profissionais da Delegacia da Mulher qualificou o atendimento psicológico ao homem como fundamental. A pesquisa demonstrou que esse atendimento psicológico é acionado principalmente por três motivos: 1) porque os homens autores de violência contra a mulher são considerados "doentes", "com algum distúrbio"; 2) para que eles tenham "consciência" do crime cometido; e 3) para que eles sejam ressocializados e devolvidos à sociedade.

É admirável a importância atribuída ao atendimento ao homem, porém, é questionável o status de "desvairado" concedido a ele. Cai-se em um antigo erro, infelizmente ainda muito comum, de achar que só os "loucos" precisam de atendimento psicológico. Essa perspectiva mais uma vez retira a implicação dos casos de violência contra a mulher das relações de gênero vividas, com suas desigualdades e injustiças, e a localiza na "mente insana" dos homens. A “culpa" recai em um "distúrbio mental" e não nas relações conflituosas que homens e mulheres (é importante frisar isso) estabelecem. Assim, o homem que agride uma mulher é um "doente" ou por ser dependente de álcool ou por ter "problemas mentais".

Contudo, esse não é o único motivo pelo qual o atendimento ao homem é indicado pelos participantes da pesquisa. A importância de atendimento profissional a esses homens (lembrem-se, encarcerados) é para que eles possam se conscientizar do erro que cometeram.

Pesquisadora: Você acha que o Estado deveria oferecer algum serviço a esse homem?

Psicóloga 2: Com certeza. Esses homens, nesse período, deveriam começar um trabalho de conscientização, de mudança dos próprios conhecimentos. Porque não é só punir. Não adianta você punir por punir se você não ensina nada com essa punição. É como se fosse uma criança que você vai bater na mão dela quando ela vai pegar o doce. E ela nem sabe, muitas vezes, porque está apanhando. Não sabe por que o doce faz mal. Você tem que explicar, você tem que conversar, você tem que propor mudanças a esse homem.

Os homens denunciados por violência contra a mulher são apresentados como pessoas que ainda têm uma concepção patriarcal ${ }^{11}$ de família, na qual o homem exerce direitos absolutos pelo que supostamente possui: esposa, filhos e patrimônio. Por conta disso, os profissionais alegam que os homens ainda não têm consciência de que é crime agredir a sua esposa, namorada etc. No trecho observado, a psicóloga chega a comparar os homens autores de violência doméstica a crianças, como se ambos não soubessem o que fazem. Essa seria, então, uma das funções do atendimento psicológico na cadeia: a de "conscientizá-los" de que violência contra a mulher é um crime.

0 terceiro motivo indicado para o atendimento aos homens está diretamente relacionado com o segundo: como a prisão é fortemente acompanhada de reincidência, é preciso conscientizar os homens de que a violência contra a mulher é crime para que ele possa ser devolvido à sociedade com "segurança".

${ }^{11}$ Seguindo Oliveira (2004), o patriarcalismo é definido de modo muito simples: como poder efetivo e socialmente sancionado da figura do pai dentro do núcleo familiar.

Psicol. Argum. 2013 jul./set., 31 (74), 425-435 
A questão passa a ser a possibilidade de "ressocializar" o homem autor de violência.

Essa perspectiva de recuperação aumenta a intolerância para com os homens que cometem violência, uma vez que os posicionam como a parte da sociedade que deve ser saneada pelos virtuosos (os representantes das tecnologias médicas e terapêuticas, como policiais, psicólogos etc.) que os tiram de circulação para formatá-los e, posteriormente, devolvê-los ao chamado "convívio social" (Dantas \& Méllo, 2008). Trata-se de um processo só punitivo! Esquecemo-nos de que não há "agressores" fora das redes sociais que os fabricam.

Mais do que aprisionar esses homens ou oferecer um "tratamento psicológico" que sirva como mais uma tecnologia de controle, seria proporcionar um espaço de escuta para homens e mulheres. Não é "tratamento", mas sim escuta e reflexão capazes de instaurar a dúvida nas certezas que produzem e mantêm situações de violência conjugal, isto é, tentar questionar as relações de gênero que produzem a violência contra a mulher.

Não queremos com isso suprimir responsabilidades dos homens pelos atos de violência que praticam contra mulheres, mas atentar para o fato de que os homens "agressores" não existem por si só: existem dentro de uma rede que os produzem. Uma rede constituída por homens, mulheres, leis, relações de gêneros, uma "cultura machista", entre outras coisas que tornam possível essas situações de violência contra a mulher.

\section{Considerações finais}

A Lei Maria da Penha trouxe como estratégia para o que ela chama de "coibir a violência doméstica e familiar" as punições mais rígidas aos considerados "agressores". É interessante notar que os/as profissionais que trabalham diretamente com essa temática consideram esse homem como um "agressor" especialmente por ele ter sido socializado em uma cultura machista. É uma nova naturalização: a essência abre espaço à socialização. Contudo, mesmo com tal consideração, todos/as os/as entrevistados/as indicam a prisão como um dos encaminhamentos (o mais importante, pelo menos) aos considerados "agressores".

A Lei Maria da Penha tem efeitos certamente positivos, sendo o principal deles o fato de que as gerações pós-lei já terem conhecimento de que a violência contra a mulher é um crime, com lei específica para combatê-lo. Esse fato já pode gerar entre as pessoas maneiras alternativas para lidar com as situações conflituosas. Esta, sem dúvida, pode ser uma grande conquista que a Lei Maria da Penha traz para a sociedade: dar visibilidade a um problema que era restrito ao ambiente familiar.

No entanto, mais do que aprisionar os homens autores de violência ou oferecer um "tratamento psicológico" que sirva como mais uma tecnologia de controle, seria interessante proporcionar um espaço de escuta para homens e mulheres envolvidos em relacionamentos violentos. É importante que seja com os homens e as mulheres, pois assim não definimos o homem simplesmente como o agressor e nem colocamos a mulher em uma passiva posição de vítima. É necessário gerar um movimento que questione o ideal de um relacionamento harmônico, fruto tanto da virtualização da instituição família (considerada santa) quanto das alegações que relações afetivas devem durar para sempre. Esses dois aspectos compõem o que estamos chamando de "virtualização da família e das relações afetivas". Claro que, agregada a essa discussão, emerge a necessidade de outra crítica importante: a normalização da heterossexualidade com seus padrões de pares opostos (homem vs. mulher).

O que se pretende a partir disso é repensar as formas de relacionamentos afetivos. Por isso a importância de se estudar os homens, seus posicionamentos, suas diferentes formas de ser, posto que homem (assim como mulher) não é uma categoria natural, mas um emaranhado que se ramifica, que se torna outros a cada momento. É em direção à construção de outros homens, mulheres, relações de gênero e afetivas que devemos direcionar nossos esforços e desejos. 


\section{Referências}

Arilha, M., Unbehaum, S., \& Medrado, B. (Org.). (2001). Homens e masculinidades: Outras palavras. São Paulo: ECOS/Editora 34.

Barbier, R. (1985). A pesquisa-ação na instituição educati$v a$. Rio de Janeiro: Jorge Zahar.

Berger, P., \& Luckmann, T. (1973). A construção social da realidade. Petrópolis: Vozes.

Brandão, C. R. (1984). Participar-pesquisar. In C. R. Brandão (Org.). Repensando a pesquisa participante. (pp. 7-14). São Paulo: Brasiliense.

Brasil (1984). Lei n. 7.210 de 11 Julho de 1984. Institui a Lei de Execução Penal. Brasília. Recuperado em 9 set. 2012, de http://www.planalto.gov.br/ccivil_03/leis/ 17210.htm

Brasil (2006). Lei n. 11.340 de 7 de agosto de 2006. Cria mecanismos para coibir a violência doméstica e familiar contra a mulher, nos termos do $§ 8^{\circ}$ do Art. 226 da Constituição Federal, da Convenção sobre a Eliminação de Todasas Formas de Discriminação contra as Mulheres e da Convenção Interamericana para Prevenir, Punir e Erradicar a Violência contra a Mulher; dispõe sobre a criação dos Juizados de Violência Doméstica e Familiar contra a Mulher; altera o Código de Processo Penal, o Código Penal e a Lei de Execução Penal; e dá outras providências. Brasília. Recuperado em 9 set. 2013, de http:// www.planalto.gov.br/ccivil_03/_ato2004-2006/ 2006/lei/l11340.htm

Costa, J. F. (1984). Violência e psicanálise. Rio de Janeiro: Graal.

Dantas, B. M., \& Méllo, R. P. (2008). Posicionamentos críticos e éticos sobre a violência contra as mulheres. Psicologia \& Sociedade, 20(n. especial), 78-86.

Deleuze, G. (1991). Foucault. São Paulo: Brasiliense.

Ezpeleta, J., \& Rockwell, E. (1986). Pesquisa participante. São Paulo: Cortez; Campinas: Autores Associados.

Foucault, M. (2003). Vigiar e punir. Petrópolis: Vozes.

Foucault, M. (2000). Sobre a prisão. In M. Foucault. Microfísica do poder (pp.129-143). Rio de Janeiro: Graal.
Furtado, L. E. (2010). Passos e espaços: Violência conjugal e ingestão de bebida alcoólica. Dissertação de Mestrado em Psicologia, Universidade Federal do Ceará, Fortaleza.

Girard, R. (1990). A violência e o sagrado. Rio de Janeiro: Paz e Terra.

Gregori, M. F. (1993). Cenas e queixas: Um estudo sobre mulheres, relações violentas e a prática feminista. Rio de Janeiro: Paz e Terra; São Paulo: ANPOCS.

Houaiss, A. (2001). Dicionário Houaiss da Língua Portuguesa. Rio de. Janeiro: Ed. Objetiva.

Latour, B. (2001). A esperança de Pandora: Ensaios sobre a realidade dos estudos científicos. Bauru: Edusc.

Mallnowski, B. (1978). Argonautas do Pacífico Ocidental. São Paulo: Abril Cultural.

Méllo, R. P., \& Furtado, L. E. (2010). Corpos e espaços híbridos na Delegacia da mulher em Fortaleza. Gerais: Revista Interinstitucional de Psicologia, 3(1), 42-51.

Mendes, J. M. (2004) Perguntar e observar não basta, é preciso analisar: algumas reflexões metodológicas. Recuperado em 16 abr. 2004, de http://www.ces. uc.pt/publicacoes/oficina/194/194.pdf

Oliveira, P. P. (2004). A construção social da masculinidade. Belo Horizonte: Editora UFMG; Rio de Janeiro: IUPERJ.

Pinheiro, O. G. (2000). Entrevista: uma prática discursiva. In M. J. Spink (Org.). Práticas Discursivas e Produção de Sentidos no Cotidiano: aproximações teóricas e metodológicas. (pp. 183-214). São Paulo: Cortez.

Psicol. Argum. 2013 jul./set., 31 (74), 425-435 